\title{
RECOBRIMENTO DE SEMENTES DE SOJA COM MICRONUTRIENTES, FUNGICIDA E POLÍMERO ${ }^{1}$
}

\author{
RODRIGO BAYS ${ }^{2}$, LEOPOLDO BAUDET $^{3}$, ADEMIRASSIS HENNING $^{4}$, ORLANDO LUCCAFILHO $^{5}$
}

\begin{abstract}
RESUMO - A técnica do recobrimento de sementes vem sendo utilizada com a finalidade de incorporar produtos fitossanitários, hormônios, micronutrientes, agentes biológicos e polímeros que propiciem um melhor desempenho de sementes e plântulas. O objetivo principal deste trabalho foi avaliar o efeito do recobrimento das sementes de soja cv. BRS 153 na qualidade das sementes e no desempenho das plântulas. O revestimento foi realizado com três doses de micronutrientes (CoMoB): 1, 2 e 4mL por quilo de sementes; um fungicida com mistura de Carbendazim + Thiram (Derosal Plus ${ }^{\circledR}$ ) e um complexo polímero + corante (Laborsan Red Solid Pam Bril ${ }^{\circledR}$ ). As avaliações da qualidade das sementes foram realizadas através do teste de germinação, índice de velocidade de germinação, envelhecimento acelerado, comprimento de plântula e emergência em casa de vegetação submetendo as sementes a um estresse hídrico de uma semana e emergência em campo. A aplicação conjunta de fungicidas, micronutrientes e polímero assegura melhor uniformidade aos tratamentos (aderência, distribuição e coloração) e não prejudica na qualidade e desempenho das sementes de soja até o limite de $2 \mathrm{~mL}$ de micronutrientes por quilograma de sementes. A dose de micronutriente de $4 \mathrm{~mL}$ / $\mathrm{kg}$ de sementes é fitotóxica.
\end{abstract}

Termos para indexação: Glycine max, revestimento, qualidade fisiológica.

\section{SOYBEAN SEED COATING WITH MICRONUTRIENTS, FUNGICIDEAND POLYMER}

\begin{abstract}
Seed coating is being used to incorporate pesticides, biological hormones, micronutrients and polymers that provide better performance for seeds, seedlings and plants in advanced stages of the crop. The main objective of this study was to evaluate the effect of soybean seed cv. BRS 153 coating on seed quality and seedling performance. Coating was made with three doses of micronutrients: $1 ; 2$ and $4 \mathrm{~mL} / \mathrm{kg}$ seeds; one fungicide: Derosal Plus ${ }^{\circledR}$ (Carbendazim + Thiram) and a polymer (Laborsan Red Solid Pam Bril ${ }^{\circledR}+$ color agent). Evaluations were made in the laboratory, greenhouse and in the field and consisted of standard germination, first count of germination, accelerated ageing, seedling length, emergence and germination speed index in the greenhouse and field emergence; The results allowed the following conclusions: a) coating soybean seeds with micronutrients, fungicide and polymer provide better uniformity (adherence, distribution and coloration) to the seeds. b) soybean seed coating does not affect its quality and performance up to $2 \mathrm{~mL}$ micronutrient per $\mathrm{kg}$ of seed, if a limit of $6 \mathrm{~mL}$ final liquid mixture per $\mathrm{kg}$ is observed; and c) micronutrient dosage of $4 \mathrm{~mL} / \mathrm{kg}$ seed is phytotoxic when seeds are coated.
\end{abstract}

Index terms: Glycine max, encapsulation, physiological quality.

\footnotetext{
${ }^{1}$ Submetido em 12/02/2006. Aceito para publicação em 19/01/2007. Parte da Dissertação de Mestrado do primeiro autor apresentada a FAEM/UFPel;

${ }^{2}$ Eng. Agrônomo, Mestre pelo PPG em Ciência e Tecnologia de Sementes, FAEM/UFPel, r6bays@gmail.com;

${ }^{3}$ Eng. Agrônomo, Ph.D., Professor Titular, Departamento de Fitotecnia,
}

FAEM/UFPel, C.P.354, 96001-900 Pelotas, RS. Bolsista de produtividade em pesquisa do CNPq. Imbaudet@ufpel.edu.br;

${ }^{4}$ Eng. Agrônomo, Ph.D., pesquisador, Embrapa-CNPSOJA, Londrina, PR; ${ }^{5}$ Eng. Agrônomo, Dr., Professor Associado, Depto. de Fitotecnia, FAEM/ UFPel. 


\section{INTRODUÇÃO}

O recobrimento de sementes é uma técnica usada há bastante tempo, principalmente em hortaliças, florestais e ornamentais. Consiste num mecanismo de aplicação de materiais inertes e adesivos, objetivando aumentar o tamanho da semente, bem como alterar sua forma e textura para facilitar a semeadura direta. Além disso, apresenta a vantagem de possibilitar a utilização conjunta de nutrientes, fungicidas, inseticidas, herbicidas e microorganismos benéficos (Nascimento et al., 1993).

No Brasil, para as grandes culturas, o recobrimento de sementes ainda é considerado uma nova tecnologia pois faltam muitas informações técnico-científicas. A agregação de valor às sementes, utilizando métodos e tecnologias de produção como a de recobrimento, vem sendo uma exigência do mercado, cada vez mais competitivo. Para isto são necessárias sementes com alta uniformidade de germinação/emergência (vigor) e que produzam plântulas com alto potencial de crescimento (Baudet e Peres, 2004).

O principal objetivo do recobrimento é melhorar o comportamento da semente, tanto do ponto de vista fisiológico como econômico (Sampaio e Sampaio, 1994). Desta forma, uma extensa revisão sobre as implicações do recobrimento das sementes com macro e micronutrientes foi apresentada por Scott (1989). Nesta revisão estão descritos os resultados positivos encontrados por vários pesquisadores sobre: 1) êxitos no estabelecimento de espécies forrageiras recobertas; 2) incremento na sobrevivência de plântulas de espécies olerícolas em semeadura direta no campo; 3) aumento na produção total dos cultivos; 4) correção da acidez do solo na área circundante às sementes; 5) maior desenvolvimento de plantas e um acesso mais uniforme de todas as plântulas aos nutrientes fornecidos. Em alguns casos a eficiência do recobrimento das sementes no fornecimento precoce de nutrientes às plantas foi significativamente maior do que a adição dos mesmos diretamente no sulco de semeadura.

Nos últimos anos, a velocidade com que as pesquisas aperfeiçoam as técnicas de revestimento para as mais distintas espécies de sementes, fez as informações, tanto sobre os produtos como sobre as metodologias disponíveis na literatura mudarem rapidamente. Portanto, considerando a importância e a grande quantidade de fatores e suas interações envolvidas nesta técnica, torna-se necessário manter estudos contínuos e aprofundados (Sampaio e Sampaio, 1994).

O objetivo deste estudo foi avaliar a qualidade fisiológica das sementes de soja BRS 153 após a aplicação de fungicida, micronutrientes (CoMoB) e o recobrimento com polímero comercial.

\section{MATERIALE MÉTODOS}

O experimento foi conduzido no Laboratório de Análise de Sementes da Universidade Federal de Pelotas - UFPel e no Centro Nacional de Pesquisa da Soja (CNPSo), em Londrina, PR.

Foram utilizadas sementes de soja da cultivar BRS 153, produzidas na safra 2003/2004 na região de Vacaria, RS, com germinação de $92 \%$ e grau de umidade de $11,2 \%$.

Para o recobrimento das sementes foi utilizado o produto de formulação líquida da empresa LABORSAN ${ }^{\circledR}$, da marca comercial LABORSAN Corantes, na dose de $2 \mathrm{~mL} \mathrm{~kg}^{-1}$ de sementes.

O fungicida utilizado foi o produto comercial sistêmico mais contato, Derosal Plus ${ }^{\circledR}$ (Carbendazim 30g i.a/kg + Thiram $70 \mathrm{~g}$ i.a/kg), classe toxicológica 3, na dose recomendada para a cultura da soja de $200 \mathrm{~mL}$ de produto comercial por $100 \mathrm{~kg}$ ${ }^{1}$ de sementes.

Para os micronutrientes foram utilizadas as doses 1,0; 2,0 e 4,0 mL de fertilizante comercial de formulação líquida Agromix (CoMoB), para cada quilograma de sementes com as seguintes concentrações: Mo - 12\%, Co - 1\% e B - $1 \%$.

O recobrimento e o tratamento das sementes foram feitos em sacos plásticos com capacidade para 5L utilizando $1 \mathrm{~kg}$ de sementes por saco. Foram utilizadas 64 unidades experimentais (dezesseis tratamentos e quatro repetições) que foram completadas com água para um volume final da calda de $6 \mathrm{~mL}$ por quilograma de sementes. Após o recobrimento, as sementes foram secadas artificialmente empregando ar de secagem aquecido com resistência elétrica de 1000 watts a temperatura de $40^{\circ} \mathrm{C}$, utilizando um equipamento similar a um secador de cabelo.

O recobrimento foi avaliado através de uma escala de avaliação visual de qualidade (Burris, s.d.) que varia de 0 (semente nua) a 10 (excelente cobertura), onde é possível observar se o recobrimento proporcionou sementes uniformes e de boa aparência.

A qualidade fisiológica das sementes foi avaliada através dos testes:

Germinação - conduzido com quatro subamostras de 50 sementes por unidade experimental, utilizando como substrato rolos-de-papel Germitest, previamente umedecidos com água na quantidade de 2,5 vezes o seu peso inicial. Os rolos foram mantidos em germinador regulado a $25^{\circ} \mathrm{C}$. As 
contagens foram realizadas unicamente no quinto dia após a semeadura.

Primeira contagem de germinação - aproveitou-se o próprio teste de germinação conduzido de acordo com as Regras para Análise de Sementes (Brasil, 1992). Foram consideradas plântulas normais as que apresentavam comprimento da parte aérea superior a $3,75 \mathrm{~cm}$ na primeira contagem do teste de germinação, que foi realizada ao terceiro dia após a semeadura.

Envelhecimento acelerado - amostras com 40 a 45 gramas de sementes foram colocadas sobre uma tela adaptada em gerbox contendo $40 \mathrm{ml}$ de água no seu interior. As sementes foram levadas a uma câmara de envelhecimento acelerado por um período de 48 horas a $41^{\circ} \mathrm{C}$ (Krzyzanowski et al, 1999). Após esse período as sementes foram submetidas ao teste de germinação (Brasil, 1992).

Comprimento de plântula e hipocótilo - realizado em cinco subamostras de 20 sementes por rolo-de-papel, de acordo com os procedimentos recomendados por Krzyzanowski et al. (1999).

Emergência em casa de vegetação - realizado em bandejas plásticas de $30 \times 20 \times 10 \mathrm{~cm}$ contendo solo não esterilizado. A semeadura foi efetivada manualmente a uma profundidade de $3 \mathrm{~cm}$, utilizando 100 sementes por unidade experimental num total de 64 bandejas. Inicialmente, as sementes foram submetidas a estresse hídrico de uma semana. Após esse período, o solo foi irrigado diariamente. A contagem das plântulas emergidas foi feita ao décimo quarto dia após a semeadura.

Emergência em campo - realizada no campo experimental da Embrapa Soja em Londrina, PR. Ao todo foram semeadas 64 parcelas em quatro linhas contendo 100 sementes por linha. A avaliação ocorreu no décimo quarto dia após a semeadura.

Procedimento estatístico - nos experimentos de campo e casa-de-vegetação foi empregado o delineamento em blocos casualizados e nos de laboratório o delineamento foi inteiramente casualizado com os tratamentos arranjados em esquema fatorial $2 \times 2 \times 4$ (fungicida, polímero e micronutrientes) com quatro repetições. Os efeitos dos tratamentos foram comparados pelo teste de Duncan a 5\% de probabilidade.

\section{RESULTADOS E DISCUSSÃO}

Os resultados do teste de germinação (Tabela 1) mostram que não houve diferença significativa quando não foi utilizado o fungicida junto com o material de recobrimento. Porém com a adição do fungicida e o polímero, houve um decréscimo significativo de germinação na dose de micronutriente $4 \mathrm{~mL}$ $\mathrm{kg}^{-1}$. Da mesma forma, nas doses de $1 \mathrm{~mL} \mathrm{~kg}^{-1}$ (baixa) e $4 \mathrm{~mL}$ $\mathrm{kg}^{-1}$ (alta) de micronutriente, a aplicação de fungicida reduziu significativamente a germinação das sementes.

Para o teste de primeira contagem da germinação (Tabela 2 ), que estima o vigor relativo das sementes, repeteu-se o efeito anterior quanto à adição de polímero e fungicida na dose de micronutriente $4 \mathrm{~mL} \mathrm{~kg}^{-1}$. Quando o fungicida foi adicionado junto ao polímero na dose de $4 \mathrm{~mL} \mathrm{~kg}^{-1}$, houve redução significativa do vigor, similar a não adição de micronutriente.

Os valores da germinação e primeira contagem variaram pouco em relação às sementes com ou sem polímero, não

TABELA 1. Germinação (\%) aos 5 dias de sementes de soja, submetidas ao recobrimento com fungicida, micronutriente e polímero, Pelotas, RS, 2003/04.

\begin{tabular}{lccc}
\hline Polímero & Micronutriente & Sem Fungicida & Com Fungicida \\
\hline \multirow{3}{*}{ Sem Polímero } & Sem Micronutriente & $94 \mathrm{~A}$ & $91 \mathrm{~A}$ \\
& $\mathrm{M} 1(2 \mathrm{~mL})$ & $92 \mathrm{~A}$ & $90 \mathrm{~A}$ \\
& $\mathrm{M} 2(1 \mathrm{~mL})$ & $94 \mathrm{~A}$ & $88 \mathrm{~B}$ \\
\hline Médias & $\mathrm{M} 3(4 \mathrm{~mL})$ & $91 \mathrm{~A}$ & $90 \mathrm{~A}$ \\
\hline \multirow{4}{*}{ Com Polímero } & & 93 & 90 \\
& Sem Micronutriente & $92 \mathrm{aA}$ & $89 \mathrm{aA}$ \\
& $\mathrm{M} 1(2 \mathrm{~mL})$ & $92 \mathrm{aA}$ & $89 \mathrm{aA}$ \\
Médias & $\mathrm{M} 2(1 \mathrm{~mL})$ & $92 \mathrm{aA}$ & $88 \mathrm{aB}$ \\
\hline Fungicida & $\mathrm{M} 3(4 \mathrm{~mL})$ & $89 \mathrm{aA}$ & $83 \mathrm{bB}$ \\
\hline C.V. $(\%)$ & & 92 & 87 \\
\hline
\end{tabular}

As médias seguidas de mesma letra, minúsculas nas colunas e maiúsculas nas linhas, não diferem entre si pelo teste de Duncan, a 5\% de probabilidade. 
sendo observados diferença ou qualquer indício de danos quando a dose de micronutriente utilizada foi de $2 \mathrm{~mL} \mathrm{~kg} \mathrm{~kg}^{-1}$, seja com ou sem fungicida. Essa redução da germinação constatada quando a dose de micronutriente foi de $4 \mathrm{~mL} \mathrm{~kg}{ }^{-1}$, juntamente com o polímero e fungicida, pode ter acontecido devido a um efeito fitotóxico do micronutriente que em excesso e ao ser envolvido pelo fungicida e o polímero, acarretaram na redução da germinação. Outro fator a ser destacado esta relacionado ao volume final da calda (fungicida + micronutriente e polímero), utilizado em todo o processo de recobrimento. Segundo Henning (2004), o produtor deve tomar cuidado ao adquirir os produtos, optando sempre por formulações líquidas que possibilitem que o volume final da calda não ultrapasse a $300 \mathrm{~mL} / 50 \mathrm{~kg}$ de sementes. No caso do presente trabalho, o volume final da calda na dose de micronutriente $4 \mathrm{~mL} \mathrm{~kg} \mathrm{~kg}^{-1}$ juntamente com o fungicida e polímero ultrapassou a recomendação descrita anteriormente, chegando a um volume final de $8 \mathrm{~mL} \mathrm{~kg}^{-1}$ de sementes ou $400 \mathrm{~mL} / 50 \mathrm{~kg}$ de sementes, o que teria prejudicado o desenvolvimento normal das plântulas.

Os resultados encontrados para o teste de envelhecimento acelerado (Tabela 3) indicam que não houve diferença significativa entre as sementes que foram submetidas ao estresse com polímero e micronutriente em todas as doses analisadas.

Com a adição do fungicida, micronutriente e polímero os valores foram similares, diferindo somente na dose de micronutriente $4 \mathrm{~mL} \mathrm{~kg}^{-1}$. A incorporação de diferentes materiais (fungicida + micronutriente e polímero) junto ao recobrimento das sementes não afetou adversamente o potencial de

TABELA 2. Primeira contagem da germinação (\%) aos 3 dias de sementes de soja, submetidas ao recobrimento com fungicida, micronutriente e polímero, Pelotas, RS, 2003/04.

\begin{tabular}{|c|c|c|c|}
\hline Polímero & Micronutriente & Sem Fungicida & Com Fungicida \\
\hline \multirow{4}{*}{ Sem Polímero } & Sem Micronutriente & $90 \mathrm{aA}$ & $86 \mathrm{aA}$ \\
\hline & $\mathrm{M} 1(2 \mathrm{~mL})$ & $90 \mathrm{aA}$ & $89 \mathrm{aA}$ \\
\hline & $\mathrm{M} 2(1 \mathrm{~mL})$ & $91 \mathrm{aA}$ & $87 \mathrm{aA}$ \\
\hline & $\mathrm{M} 3(4 \mathrm{~mL})$ & $91 \mathrm{aA}$ & $88 \mathrm{aA}$ \\
\hline Médias & & 91 & 87 \\
\hline \multirow{4}{*}{ Com Polímero } & Sem Micronutriente & $90 \mathrm{aA}$ & $83 \mathrm{abB}$ \\
\hline & $\mathrm{M} 1(2 \mathrm{~mL})$ & $88 \mathrm{aA}$ & $86 \mathrm{aA}$ \\
\hline & $\mathrm{M} 2(1 \mathrm{~mL})$ & $87 \mathrm{aA}$ & $88 \mathrm{aA}$ \\
\hline & $\mathrm{M} 3(4 \mathrm{~mL})$ & $85 \mathrm{aA}$ & $78 \mathrm{bB}$ \\
\hline Médias & & 87 & 84 \\
\hline Fungicida & & $89 \mathrm{~A}$ & $85 \mathrm{~B}$ \\
\hline C.V. $(\%)$ & 4,61 & & \\
\hline
\end{tabular}

As médias seguidas de mesma letra, minúsculas nas colunas e maiúsculas nas linhas, não diferem entre si pelo teste de Duncan, a 5\% de probabilidade.

TABELA 3. Envelhecimento acelerado (\%) de sementes de soja, submetidas ao recobrimento com fungicida, micronutriente e polímero, Pelotas, RS, 2003/04.

\begin{tabular}{lccc}
\hline Polímero & Micronutriente & Sem Fungicida & Com Fungicida \\
\hline \multirow{3}{*}{ Sem Polímero } & Sem Micronutriente & $91 \mathrm{aA}$ & $88 \mathrm{aB}$ \\
& M1 $(2 \mathrm{~mL})$ & $90 \mathrm{aA}$ & $91 \mathrm{aA}$ \\
& M2 $(1 \mathrm{~mL})$ & $91 \mathrm{aA}$ & $90 \mathrm{aA}$ \\
& M3 $(4 \mathrm{~mL})$ & $91 \mathrm{aA}$ & $90 \mathrm{aA}$ \\
\hline Médias & & 91 & 90 \\
\multirow{3}{*}{ Com Polímero } & Sem Micronutriente & $90 \mathrm{aA}$ & $90 \mathrm{aA}$ \\
& $\mathrm{M} 1(2 \mathrm{~mL})$ & $90 \mathrm{aA}$ & $90 \mathrm{aA}$ \\
& $\mathrm{M} 2(1 \mathrm{~mL})$ & $90 \mathrm{aA}$ & $90 \mathrm{aA}$ \\
Médias & $\mathrm{M} 3(4 \mathrm{~mL})$ & $90 \mathrm{aA}$ & $88 \mathrm{aB}$ \\
\hline Fungicida & & 90 & 90 \\
\hline C.V. $(\%)$ & & $90 \mathrm{~A}$ & $90 \mathrm{~A}$ \\
\hline
\end{tabular}

As médias seguidas de mesma letra, minúsculas nas colunas e maiúsculas nas linhas, não diferem entre si pelo teste de Duncan, a 5\% de probabilidade. 
armazenamento, podendo agregar valor às sementes comercializadas quando aplicada à dose de micronutriente até $2 \mathrm{~mL} \mathrm{~kg}^{-1}$.

Embora as sementes tratadas apresentem porcentagens mais altas de germinação após o envelhecimento, segundo Marcos Filho \& Shioga (1981), o uso de fungicidas não promove modificações acentuadas nas informações sobre 0 potencial fisiológico das amostras avaliadas. Porém, esses resultados devem ser encarados com a devida cautela, o apoio da patologia de sementes é fundamental para elucidar as relações fungicidas/patógenos, sabendo também que, tanto a temperatura como a umidade elevada, inibem a manifestação de certos microrganismos. Assim, os dados obtidos num teste de envelhecimento acelerado podem ser superiores aos observados no teste de germinação conduzido com a mesma amostra.

Nos testes de comprimento de plântula e hipocótilo, segundo Krzyzanowski et al. (1999), o objetivo principal é estimar o vigor relativo do lote de sementes. Essas considerações são válidas, sementes vigorosas originam plântulas com altas taxas de crescimento e capacidade de transformação, maior suprimento de reservas dos tecidos de armazenamento, e também elevada incorporação destes pelo eixo embrionário (Dan et al., 1987). Os resultados encontrados para o teste de comprimento de plântula (Tabela 4) indicam que não houve diferença significativa no comprimento das plântulas com polímero e micronutriente em todas as doses analisadas. Com a adição do fungicida, micronutriente e polímero, os valores sofreram pequenas variações, porém houve diferença na dose de micronutriente $4 \mathrm{~mL} \mathrm{~kg}^{-1}$. A mesma tendência foi encontrada no teste de comprimento de hipocótilo
(Tabela 5), onde os valores variaram na dose de micronutriente $4 \mathrm{~mL} \mathrm{~kg}^{-1}$. Em ambos os testes a tecnologia de recobrimento das sementes é perfeitamente viável, desde que utilizada a dose de micronutriente $2 \mathrm{~mL} \mathrm{~kg}^{-1}$ juntamente com fungicida e polímero.

Na Tabela 6 pode-se observar que ocorreu aumento significativo na emergência em casa-de-vegetação das plântulas que receberam o recobrimento com fungicida, micronutriente e polímero em relação às sementes não recobertas desde que respeitada a dose de micronutriente de no máximo $2 \mathrm{~mL} \mathrm{~kg}^{-1}$. Um fato também muito importante a ser destacado em relação à emergência em casa-de-vegetação é que diferentemente dos resultados encontrados no laboratório, a emergência das plântulas se comportou positivamente com a adição de fungicida junto ao micronutriente em todas as doses. Estes resultados estão de acordo com Krzyzanowski et al. (1999), pois o tratamento químico das sementes, principalmente com produtos fungicidas, é fator que pode alterar o desempenho do teste em condições de laboratório. Observou-se que as sementes ao serem submetidas a um estresse hídrico simulando as condições que podem ocorrer no campo, o fungicida assegurou melhores resultados na emergência, todavia não diferindo em todas as dose de micronutriente. Resultados semelhantes foram encontrados por Zorato et al. (2001) que demonstraram que o tratamento de sementes com fungicida, além de controlar patógenos importantes transmitidos via semente, é uma prática importante para assegurar populações adequadas de plantas quando as condições de clima e solo são desfavoráveis.

A dose de micronutriente $4 \mathrm{~mL} \mathrm{~kg}^{-1}$ foi prejudicial na

TABELA4. Comprimento (mm) de plântula originadas de sementes de soja, submetidas ao recobrimento com fungicida, micronutriente e polímero, Pelotas, RS, 2003/04.

\begin{tabular}{lccc}
\hline Polímero & Micronutriente & Sem Fungicida & Com Fungicida \\
\hline \multirow{4}{*}{ Sem Polímero } & Sem Micronutriente & $30,32 \mathrm{aA}$ & $28,41 \mathrm{aA}$ \\
& M1 $(2 \mathrm{~mL})$ & $28,44 \mathrm{aA}$ & $29,09 \mathrm{aA}$ \\
& M2 $(1 \mathrm{~mL})$ & $28,37 \mathrm{aA}$ & $29,16 \mathrm{aA}$ \\
\hline Médias & M3 $(4 \mathrm{~mL})$ & $30,83 \mathrm{aA}$ & $26,36 \mathrm{aB}$ \\
\hline \multirow{4}{*}{ Com Polímero } & & 29,50 & 28,25 \\
& Sem Micronutriente & $27,69 \mathrm{aA}$ & $28,92 \mathrm{aA}$ \\
& $\mathrm{M} 1(2 \mathrm{~mL})$ & $29,46 \mathrm{aA}$ & $29,60 \mathrm{aA}$ \\
& $\mathrm{M} 2(1 \mathrm{~mL})$ & $28,81 \mathrm{aA}$ & $28,05 \mathrm{abA}$ \\
Médias & $\mathrm{M} 3(4 \mathrm{~mL})$ & $27,30 \mathrm{aA}$ & $25,26 \mathrm{bB}$ \\
\hline Fungicida & & 28,32 & 27,96 \\
\hline C.V. $(\%)$ & 7,53 & $28,90 \mathrm{~A}$ & $28,10 \mathrm{~A}$ \\
\hline
\end{tabular}

As médias seguidas de mesma letra, minúsculas nas colunas e maiúsculas nas linhas, não diferem entre si pelo teste de Duncan, a 5\% de probabilidade. 
TABELA 5. Comprimento (mm) de hipocótilo de plântulas originadas de sementes de soja, submetidas ao recobrimento com fungicida, micronutriente e polímero, Pelotas, RS, 2003/04.

\begin{tabular}{lccc}
\hline Polimero & Micronutriente & Sem Fungicida & Com Fungicida \\
\hline & Sem Micronutriente & $9,77 \mathrm{aA}$ & $9,38 \mathrm{aA}$ \\
Sem Polímero & $\mathrm{M} 1(2 \mathrm{~mL})$ & $9,58 \mathrm{aA}$ & $9,37 \mathrm{aA}$ \\
& $\mathrm{M} 2(1 \mathrm{~mL})$ & $9,39 \mathrm{aA}$ & $9,55 \mathrm{aA}$ \\
& $\mathrm{M} 3(4 \mathrm{~mL})$ & $9,73 \mathrm{aA}$ & $8,39 \mathrm{aB}$ \\
\hline Médias & & 9,62 & 9,17 \\
\hline \multirow{4}{*}{ Com Polímero } & Sem Micronutriente & $9,60 \mathrm{aA}$ & $9,16 \mathrm{abA}$ \\
& $\mathrm{M} 1(2 \mathrm{~mL})$ & $9,59 \mathrm{aA}$ & $9,78 \mathrm{aA}$ \\
& $\mathrm{M} 2(1 \mathrm{~mL})$ & $9,54 \mathrm{aA}$ & $8,76 \mathrm{abA}$ \\
Médias & $\mathrm{M} 3(4 \mathrm{~mL})$ & $8,78 \mathrm{aA}$ & $7,97 \mathrm{bA}$ \\
\hline Fungicida & & 9,38 & 8,92 \\
\hline C.V. $(\%)$ & 10.05 & $9,50 \mathrm{~A}$ & $9,04 \mathrm{~A}$ \\
\hline
\end{tabular}

As médias seguidas de mesma letra, minúsculas nas colunas e maiúsculas nas linhas, não diferem entre si pelo teste de Duncan, a 5\% de probabilidade.

TABELA 6. Emergência (\%) em casa de vegetação de plântulas originadas de das sementes de soja, submetidas ao recobrimento com fungicida, micronutriente e polímero, Pelotas, RS, 2003/04.

\begin{tabular}{lccc}
\hline \multicolumn{1}{c}{ Polimero } & Micronutriente & Sem Fungicida & Com Fungicida \\
\hline \multirow{4}{*}{ Sem Polímero } & Sem Micronutriente & $86 \mathrm{aB}$ & $93 \mathrm{aA}$ \\
& $\mathrm{M} 1(2 \mathrm{~mL})$ & $89 \mathrm{aA}$ & $94 \mathrm{aA}$ \\
& $\mathrm{M} 2(1 \mathrm{~mL})$ & $90 \mathrm{aA}$ & $94 \mathrm{aA}$ \\
& $\mathrm{M} 3(4 \mathrm{~mL})$ & $85 \mathrm{aB}$ & $95 \mathrm{aA}$ \\
\hline Médias & & 87 & 94 \\
\hline \multirow{2}{*}{ Com Polímero } & $\mathrm{S} / \mathrm{Micronutriente}$ & $86 \mathrm{aB}$ & $91 \mathrm{abA}$ \\
& $\mathrm{M} 1(2 \mathrm{~mL})$ & $90 \mathrm{aA}$ & $94 \mathrm{abA}$ \\
& $\mathrm{M} 2(1 \mathrm{~mL})$ & $85 \mathrm{aB}$ & $95 \mathrm{aA}$ \\
Médias & $\mathrm{M} 3(4 \mathrm{~mL})$ & $85 \mathrm{aB}$ & $87 \mathrm{bA}$ \\
\hline Fungicida & & 86 & 92 \\
\hline C.V. $(\%)$ & 4,82 & 87 & 93 \\
\hline
\end{tabular}

As médias seguidas de mesma letra, minúsculas nas colunas e maiúsculas nas linhas, não diferem entre si pelo teste de Duncan, a 5\% de probabilidade.

emergência das plântulas em casa-de-vegetação devido à recomendação do volume final da calda que foi ultrapassado chegando a $8 \mathrm{~mL} \mathrm{~kg}^{-1}$ de sementes.

De modo geral, as médias das variáveis analisadas para o recobrimento das sementes com fungicida, micronutriente na dose de $2 \mathrm{~mL} \mathrm{~kg}^{-1}$ e polímero não acarretou nenhum efeito prejudicial à qualidade fisiológica das sementes de soja, o que trouxe benefícios tanto no estabelecimento inicial da cultura quanto no armazenamento em condições de laboratório, tornando-se mais uma tecnologia que pode agregar valor às sementes comercializadas. A mesma tendência foi encontrada em condições de casa-de-vegetação.

Os resultados encontrados para as sementes recobertas com fungicida, micronutriente e polímero no campo mostram que não houve diferença em todas as doses de micronutrientes testadas (Tabela 7) e que os valores da emergência de plântulas originadas de sementes sem recobrimento foram significativamente inferiores, em relação a adição de fungicida na dose de $4 \mathrm{~mL} \mathrm{~kg}^{-1}$.

É muito importante destacar que esses resultados devem ser recebidos com devida cautela, pois a ocorrência abundante de chuvas durante a semeadura pode ter mascarado o efeito 
TABELA 7. Emergência (\%) em campo de plântulas originadas de sementes de soja, submetidas ao recobrimento com fungicida, micronutriente e polímero, Pelotas, RS, 2003/04.

\begin{tabular}{lccc}
\hline \multicolumn{1}{c}{ Polimero } & Micronutriente & Sem Fungicida & Com Fungicida \\
\hline \multirow{3}{*}{ Sem Polímero } & Sem Micronutriente & $52 \mathrm{bB}$ & $66 \mathrm{aA}$ \\
& M1 $(2 \mathrm{~mL})$ & $64 \mathrm{aA}$ & $59 \mathrm{aA}$ \\
& M2 $(1 \mathrm{~mL})$ & $62 \mathrm{aA}$ & $60 \mathrm{aA}$ \\
\hline Médias & M3 $(4 \mathrm{~mL})$ & $68 \mathrm{aA}$ & $52 \mathrm{bB}$ \\
\hline & Sem Micronutriente & $67 \mathrm{aA}$ & $63 \mathrm{aA}$ \\
Com Polímero & M1 $(2 \mathrm{~mL})$ & $60 \mathrm{aA}$ & $62 \mathrm{aA}$ \\
& $\mathrm{M} 2(1 \mathrm{~mL})$ & $55 \mathrm{aA}$ & $56 \mathrm{aA}$ \\
\hline Médias & M3 $(4 \mathrm{~mL})$ & $64 \mathrm{aA}$ & $57 \mathrm{aA}$ \\
\hline Fungicida & & 61 & 59 \\
\hline C.V. $(\%)$ & & $61 \mathrm{~A}$ & $59 \mathrm{~A}$ \\
\hline
\end{tabular}

As médias seguidas de mesma letra, minúsculas nas colunas e maiúsculas nas linhas, não diferem entre si pelo teste de Duncan, a 5\% de probabilidade.

real que o fungicida juntamente com micronutriente e polímero poderiam propiciar no recobrimento das sementes e a emergência da soja, sendo necessários mais estudos conclusivos. Esses resultados estão de acordo com Henning et al. (2000), que testaram em dois locais (Londrina e Ponta Grossa) diversos fungicidas e suas misturas no tratamento de sementes de soja e concluiram que em solos com boa disponibilidade hídrica e temperaturas adequadas para uma rápida germinação e emergência, o tratamento de sementes com fungicida não propicia aumento na emergência da soja. Todavia, vale ressaltar a importância do tratamento de sementes, uma vez que raramente a semeadura coincide com as condições ideais de umidade do solo.

É interessante observar também que as sementes que receberam somente o polímero no material de recobrimento se comportaram positivamente em condições de campo, mostrando um possível efeito fungicida na composição química do produto, abrindo opções para novos estudos.

As sementes recobertas obtiveram nota 9,5 na escala de avaliação de Burris, mostrando uma cobertura perto do excelente, isto é com boa aparência bem como aderência, distribuição e coloração dos produtos utilizados no recobrimento.

\section{CONCLUSÕES}

A aplicação conjunta de micronutrientes até a dose de $2 \mathrm{~mL} \mathrm{~kg}^{-1}$ de sementes juntamente com o fungicida e o polímero sintético não prejudica a qualidade fisiológica da semente de soja, desde que observado o limite de $6 \mathrm{~mL} \mathrm{~kg}^{-1}$ de sementes em relação à calda final.
A dose de micronutriente $4 \mathrm{~mL} \mathrm{~kg}^{-1}$ é fitotóxica quando as sementes são recobertas com fungicida e polímero.

$\mathrm{O}$ recobrimento das sementes de soja com fungicida, micronutriente e o polímero proporciona sementes com boa aparência, aderência, distribuição e coloração.

\section{REFERÊNCIAS}

BAUDET, L.; PERES, W. Recobrimento de sementes. Seed News, Pelotas, v.8, n.1, p.20-23, 2004.

BRASIL. Ministério da Agricultura e da Reforma Agrária. Regras para análise de sementes. Brasília: SNDA/DNDV/CLAV, 1992, 365 p.

BURRIS, J. Film Coating Coverage Quality Rating Scale. Prepared by CMS. Transl. Syngenta. Ames, Seed Science Center, Iowa State University. p.1.,s.d.

DAN, E.; MELLO, V.; WETZEL, C.; POPINIGIS, F.; SOUZA, E. Transferência de matéria seca como método de avaliação de avaliação do vigor de sementes de soja. Revista Brasileira de Sementes, Brasília, v.9, n.3, p.45-55, 1987.

HENNING, A.; YORINORI, J.; FRANCA NETO, J.; KRZYZANOWSKI, F.; COSTA, N. Avaliação de fungicidas e suas misturas no tratamento de sementes de soja. Resultados da pesquisa agropecuária EMBRAPA-CNPSo. Londrina, 2000.

HENNING, A. Patologia e tratamento de sementes: noções gerais. (EMBRAPA- Documentos 235). Londrina, EMBRAPA-CNPSo, 2004, 51p.

KRZYZANOWSKI, F.; FRANCA NETO, J.; VIEIRA R. D. Vigor de sementes: conceitos e testes. Londrina, ABRATES, v.1, c.2, ítem 3, 1999.

MARCOS FILHO, J.; SHIOGA, P.S. Tratamento fungicida de sementes de soja no teste de envelhecimento rápido. Revista de Agricultura. São Paulo, v.56,n.3,p.163-172, 1981. 
NASCIMENTO, W.; SILVA, J.; MARTON, L. Qualidade fisiológica de sementes peletizadas de tomate durante o armazenamento. Informativo ABRATES. Londrina, v.3,n.3, p.47, 1993.

SAMPAIO, T.; SAMPAIO, N. Recobrimento de Sementes. Informativo ABRATES. Londrina, v.4, n.3, p.20-52, 1994.

SCOTT, J.M. Seed coatings and treatments and their effects on plant establishment. Advances in Agronomy, 42, 43-83, 1989.

ZORATO, M.; HENNING, A. Influência de tratamentos fungicidas antecipados, aplicados em diferentes épocas de armazenamento, sobre a qualidade de sementes de soja. Revista Brasileira de Sementes. Londrina, ABRATES. v.23, n.2, p. 236-244, 2001. 